\title{
Pharmacokinetics of dasatinib for Philadelphia-positive acute lymphocytic leukemia with acquired T315I mutation
}

\author{
Naoto Takahashi ${ }^{1 *}$, Masatomo Miura ${ }^{2}$, Stuart A Scott ${ }^{3}$, Takenori Niioka ${ }^{2}$ and Kenichi Sawada ${ }^{1}$
}

\begin{abstract}
Background: The BCR-ABL T315I kinase domain mutation is insensitive to dasatinib therapy for Philadelphiapositive acute lymphoid leukemia (Ph + ALL) patients. Resistant T315I clone may be present prior to initiating dasatinib, which could expand under selective pressures during treatment. However, it is also possible that Ph + ALL patients newly acquire the T315I mutation during dasatinib therapy. Despite the potent inhibition of BCR-ABL kinase by dasatinib, little is known about the relationship between dasatinib pharmacokinetics and the emergence of kinase domain mutations in vivo.

Methods: To determine whether plasma dasatinib pharmacokinetics influences the emergence of BCR-ABL mutations, we measured plasma dasatinib levels in $11 \mathrm{Ph}+\mathrm{ALL}$ patients undergoing dasatinib monotherapy.

Results: Bone marrow relapse occurred in 5 of the $11 \mathrm{Ph}+\mathrm{ALL}$ patients (45\%). Importantly, a T315I mutation was detected in 4 of the 5 relapsed patients, despite the absence of BCR-ABL mutations in any patient at baseline. The median plasma concentration at 2 hours $\left(C_{2 h}\right)$, the median plasma maximum concentration $\left(C_{\text {max }}\right)$, and the median area under the observed plasma concentration-time curve from 0 to 4 hours $\left(A \cup C_{0-4}\right)$ were all significantly lower in patients with T315I than those without the mutation $\left(C_{2 h}, 22.3 \mathrm{ng} / \mathrm{mL}\right.$ vs. $111.6 \mathrm{ng} / \mathrm{mL}, P=0.0242 ; C_{\max }, 43.8 \mathrm{ng} / \mathrm{mL}$ vs. $112.4 \mathrm{ng} / \mathrm{mL}, P=0.0242 ; \mathrm{AUC}_{0-4}, 108.3 \mathrm{ng} \cdot \mathrm{h} / \mathrm{mL}$ vs. $268.3 \mathrm{ng} \cdot \mathrm{h} / \mathrm{mL}, P=0.0061$, respectively).

Conclusions: These data indicate that the emergence of the T315I mutation among Ph + ALL patients treated with dasatinib is, in part, dependent on plasma dasatinib pharmacokinetics. Notably, these data also suggest that newly acquired BCR-ABL mutations may be inhibited by an increased exposure of dasatinib.
\end{abstract}

Keywords: Dasatinib, Ph positive acute lymphoid leukemia, T315I, Pharmacokinetics

\section{Introduction}

Dasatinib is a second-generation inhibitor of the BCR-ABL and SRC tyrosine kinases. In vitro, dasatinib inhibits the BCR-ABL kinase with 325-fold greater potency than imatinib [1]. In addition, it showed significant activity in Phase II studies in Philadelphia-positive acute lymphoid leukemia $(\mathrm{Ph}+\mathrm{ALL})$ patients who were resistant or intolerant to imatinib [2]. In pharmacokinetic studies, dasatinib exposure was shown to vary linearly and proportionally with dose. Maximum plasma concentration $\left(C_{\max }\right)$ was observed 0.5

\footnotetext{
* Correspondence: naotot@doc.med.akita-u.ac.jp

'Dept. of Hematology Nephrology and Rheumatology, Akita Univ. Graduate School of Medicine, Akita, Japan

Full list of author information is available at the end of the article
}

hours after a single oral administration, and the mean terminal elimination half-life ( $t 1 / 2)$ was $<4$ hours with rapid absorption.

Dasatinib has in vitro activity against all imatinibresistant BCR-ABL mutations, with the notable exception of T315I [1]. For example, a previous study reported that 12 of 17 relapsed Ph + ALL patients acquired a T315I mutation during dasatinib therapy [3]. Additionally, there is little data on the relationship between plasma dasatinib concentration and outcome or adverse events, and no clinically relevant data to suggest that dose changes are necessary based on sex, age, or pharmacogenetic variation in dasatinib transporters. Moreover, little is known about the relationship between dasatinib pharmacokinetics and the emergence of BCR-ABL kinase domain mutations in vivo.

\section{Biomed Central}


To determine whether plasma dasatinib pharmacokinetics influences BCR-ABL mutations, we used highperformance liquid chromatography (HPLC) to measure the plasma dasatinib concentrations in Ph + ALL patients undergoing dasatinib monotherapy.

\section{Methods}

\section{Pharmacokinetic analyses}

Plasma dasatinib concentrations prior to therapy and 1 to 4 hours after administration $\left(\mathrm{C}_{0 \mathrm{~h}}, \mathrm{C}_{1 \mathrm{~h}}, \mathrm{C}_{2 \mathrm{~h}}\right.$ and $\left.\mathrm{C}_{4 \mathrm{~h}}\right)$ on day 7 , which previously has been found to represent a stable period of dasatinib pharmacokinetics [4], were measured by HPLC. Pharmacokinetic analyses of dasatinib were performed using the standard noncompartmental method with WinNonlin (Pharsight Co., Mountain View, CA, version 4.0.1). The area under the observed plasma concentration-time curve from 0 to 4 hours $\left(\mathrm{AUC}_{0-4}\right)$ was calculated using the linear trapezoidal rule. $\mathrm{C}_{\max }$ was obtained directly from the profile.

\section{BCR-ABL Mutation analyses}

Peripheral blood samples were obtained at baseline of dasatinib initiation and at bone marrow relapse. The bcr-abl fusion transcript was analyzed for mutations using direct sequencing.

\section{Statistical analyses}

Statistical analyses were carried out using SPSS (SPSS Japan Inc., Tokyo, Japan, version 17.0) and the data are presented as medians (quartile 1-quartile 3). Differences in reported parameters between two patient groups were evaluated using the Mann-Whitney's U test. Time to event was measured from the date of dasatinib administration to the date of hematological relapse, date of death from any cause, or date of last molecular examination for patients who did not relapse. Event-free survival (EFS) was estimated using the Kaplan- Meier method. Values of $P<0.05$ were considered significant.

\section{Study conduct}

The study was conducted in accordance with the Declaration of Helsinki. Informed consent was obtained from all patients according to institutional guidelines. The study was approved by the Akita University Research Ethics Board.

\section{Results}

Eleven patients with $\mathrm{Ph}+\mathrm{ALL}$ received dasatinib monotherapy as an induction therapy according to previous study reported by Foà et al [3] (Table 1). The mean age was 59.0 years (range: $22-80$ years), and $54.5 \%$ of the patients were male. No patient had severe hepatic or renal dysfunction. Median treatment duration of dasatinib monotherapy was 221 days (151.3-355.5 days).

There were no CNS leukemia or CNS relapses among any of the patients during dasatinib monotherapy and all patients achieved hematological remission; however, bone marrow relapse was observed in 5 of the $11 \mathrm{Ph}+\mathrm{ALL}$ patients (45\%). Importantly, a T315I mutation was detected in 4 of the 5 relapsed patients by direct sequencing, despite the absence of BCR-ABL mutations in any patient at baseline. The median EFS for Ph + ALL patients with T315I was 197 days. In contrast, the median EFS for patients without T315I had not yet been reached, and the estimated 20 -month survival rate was $70 \%$.

Table 2 summarizes the comparison between clinical characteristics and dasatinib pharmacokinetics in patients with and without T315I during dasatinib therapy. With the exception of platelet count, no correlations were detected with any clinical characteristics and T315I emergence;

Table 1 Patients and clinical outcomes with dasatinib monotherapy

\begin{tabular}{|c|c|c|c|c|c|c|c|}
\hline No & Age & Sex & Dasatinib dose & BM relapse & BCR-ABL mutation & EFS, day & Outcome / Event (cause of death) \\
\hline 1 & 56 & M & $100 \mathrm{mg}$ QD & No & No & $624^{*}$ & $\mathrm{SCT}$ in $\mathrm{CMR}$ \\
\hline 2 & 56 & M & $100 \mathrm{mg}$ QD & No & No & 149 & dead (infection) \\
\hline 3 & 64 & $\mathrm{~F}$ & $100 \mathrm{mg}$ QD & No & No & 318 & CMR \\
\hline 4 & 68 & M & $100 \mathrm{mg}$ QD & Yes & T3151 & 368 & dead (PD) \\
\hline 5 & 67 & $\mathrm{~F}$ & $100 \mathrm{mg}$ QD & Yes & T315। & 197 & dead (PD) \\
\hline 6 & 22 & $\mathrm{~F}$ & $100 \mathrm{mg}$ QD & No & No & $634^{*}$ & $\mathrm{SCT}$ in CMR \\
\hline 7 & 77 & M & $50 \mathrm{mg} \mathrm{BID}$ & Yes & T315I & 221 & dead (PD) \\
\hline 8 & 63 & $F$ & $50 \mathrm{mg}$ QD & Yes & T315I & 106 & dead (PD) \\
\hline 9 & 80 & F & $100 \mathrm{mg}$ QD & No & No & 269 & CMR \\
\hline 10 & 32 & M & $100 \mathrm{mg}$ QD & No & No & 158 & CMR \\
\hline 11 & 78 & M & 100 mg QD & Yes & No & 114 & dead (PD) \\
\hline
\end{tabular}

BM, bone marrow; EFS, event-free survival; OS, overall survival; $M$, male; F, femal; $Q D$, once a day; BID, twice a day; SCT, stem cell transplantation; CMR, complete molecular response; PD, progressive disease; * a date of SCT was evaluated as censoring for analysis of EFS. 
Table 2 Comparison of the clinical characteristics and dasatinib pharmacokinetics in patients with and without a T315I mutation

\begin{tabular}{|c|c|c|c|}
\hline & T315I $(n=4)$ & Without T315I $(n=7)$ & P-Value \\
\hline & $\overline{\text { median (quartile 1- quartile 3) }}$ & $\overline{\text { median (quartile 1- quartile 3) }}$ & \\
\hline Sex ${ }^{\dagger}$ Female & $2(50.0)$ & $3(42.9)$ & 0.6515 \\
\hline Age (year) & $67(64-72)$ & $56(38.5-71)$ & 0.4121 \\
\hline Bodily weight (kg) & $50.3(48.3-60.1)$ & $49.0(44.2-52.8)$ & 0.7879 \\
\hline Body surface area $\left(\mathrm{m}^{2}\right)$ & $1.49(1.46-1.57)$ & $1.45(1.39-1.57)$ & 0.6485 \\
\hline White blood cell $\left(* 10^{3} / \mathrm{mm}^{3}\right)$ & $2.4(2.4-2.5)$ & $3.7(2.15-5.85)$ & 0.3833 \\
\hline Red blood cell $\left({ }^{*} 10^{4} \mathrm{~mm}^{3}\right)$ & $248(241-282)$ & $291(238-316)$ & 0.8333 \\
\hline Platelet $\left({ }^{*} 10^{4} / \mathrm{mm}^{3}\right)$ & $70(50.5-77.5)$ & $135(117-167)$ & 0.0167 \\
\hline Aspartate transaminase (IU/L) & $32.5(19.5-50)$ & $33(15.5-34)$ & 0.5273 \\
\hline Alanine transaminase (IU/L) & $23(21-79)$ & $23(14-73.5)$ & 0.7879 \\
\hline Serum albumin (g/dL) & $4.3(4.0-4.5)$ & $3.9(3.3-4.2)$ & 0.2303 \\
\hline Total bilirubin (mg/dL) & $0.4(0.4-0.5)$ & $0.4(0.4-0.9)$ & 0.9273 \\
\hline Serum creatinine (mg/dL) & $0.6(0.5-0.8)$ & $0.6(0.5-0.9)$ & 0.7879 \\
\hline Single dose (mg) & $100(75-100)$ & $100(100-100)$ & 0.7879 \\
\hline $\mathrm{C}_{\mathrm{oh}}(\mathrm{ng} / \mathrm{mL})$ & $0.2(0.1-0.4)$ & $0.0(0.0-0.0)$ & 0.1091 \\
\hline$C_{1 h}(n g / m L)$ & $13.2(3.3-23.8)$ & $49.0(23.6-66.7)$ & 0.0727 \\
\hline$C_{2 h}(n g / m L)$ & $22.3(5.8-43.8)$ & $111.6(65.1-122.8)$ & 0.0242 \\
\hline $\mathrm{C}_{4 \mathrm{~h}}(\mathrm{ng} / \mathrm{mL})$ & $34.6(10.6-76.3)$ & $69.7(66.9-95.3)$ & 0.1636 \\
\hline$C_{\max }(n g / m L)$ & $43.8(19.1-77.0)$ & $112.4(95.3-122.8)$ & 0.0242 \\
\hline$A \cup C_{0-4 h}(\mathrm{ng} \cdot h / m L)$ & $108.3(49.2-139.2)$ & $268.3(220.0-307.3)$ & 0.0061 \\
\hline
\end{tabular}

${ }^{\dagger}$ Data presented as numbers (\%) of patients;

$\mathrm{C}_{\mathrm{nh}}$, plasma concentration at $\mathrm{n}$ hour after dasatinib administration;

$C_{\max }$ maximum plasma concentration less than 4 hours after dasatinib administration;

$\mathrm{AUC}_{0-4 h}$, area under the plasma concentration-time curve from 0 to 4 hours.

however, significant differences in plasma $\mathrm{C}_{2 \mathrm{~h}}, \mathrm{C}_{\max }$ and $\mathrm{AUC}_{0-4 \mathrm{~h}}$ were detected between patients with $\mathrm{T} 315 \mathrm{I}$ and those without $(P=0.0242,0.0242$, and 0.0061 , respectively, Figure 1).

\section{Discussion}

The emergence of a BCR-ABL kinase domain mutation during dasatinib therapy, particularly T315I, is a significant concern that requires careful consideration of
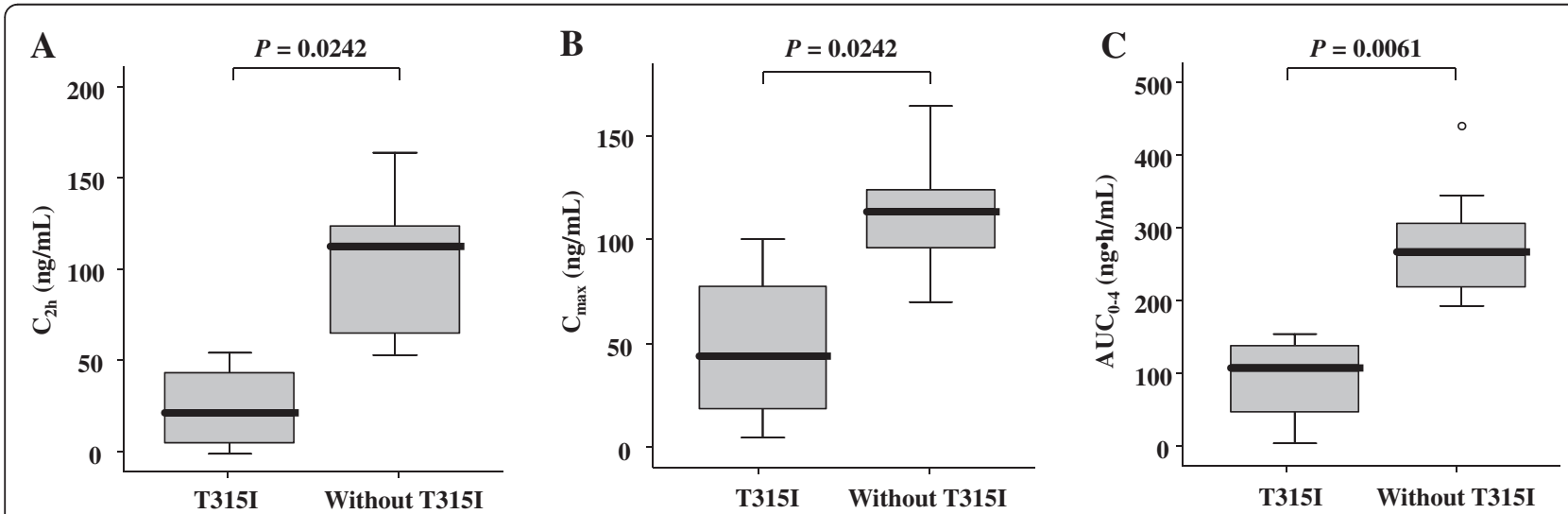

Figure 1 Comparison of clinical and pharmacokinetic parameters of dasatinib in patients with and without a T315I mutation: (A) plasma concentration $2 \mathrm{~h}$ after dasatinib administration $\left(\mathrm{C}_{2 \mathrm{~h}}\right),(\mathrm{B})$ maximum plasma concentration after dasatinib administration $\left(C_{\max }\right)$, and $(C)$ area under the plasma concentration-time curve from $\mathbf{0}$ to $\mathbf{4} \mathbf{h}\left(\mathrm{AUC}_{\mathbf{0}-4 \mathrm{~h}}\right)$. Boxes represent interquartile ranges (IQR) with the median represented by bold horizontal lines. The ends of the whiskers (vertical lines) represent the smallest and largest values that are not outliers. 
clinical management. The median time between dasatinib treatment initiation and T315I mutation detection in our study was 7.4 months (range, 3.5-12.3 months), which was similar to the 9.1 months reported in a previous retrospective study by Nicolini et al. [5].

Soverini et al. retrospectively analyzed $\mathrm{Ph}+\mathrm{ALL}$ patients treated with dasatinib by cloning the BCR-ABL kinase domain in a bacterial vector and sequencing 200 independent clones per sample. Notably, T315I was detected at diagnosis in two of six patients who relapsed [6]. Although a T315I mutation could exist prior to dasatinib treatment, evidence from both clinical trials [3] and mouse models [7] indicates that in some cases it is newly acquired as a result of selective pressures during treatment. If a resistant T315I clone was present prior to dasatinib treatment, it would likely expand under selective pressures, and its prevention likely requires a novel agent targeting T315I leukemia. However, if a resistant T315I clone was newly acquired during proliferation due to insufficiency of dasatinib therapy, it may be possible to prevent acquired genetic tyrosine kinase mutations by an increased exposure of dasatinib.

An effective transient dasatinib level of $100 \mathrm{nM}$ (approximately $50 \mathrm{ng} / \mathrm{mL}$ ) is sufficient to inhibit the in vitro proliferation of most cell lines expressing imatinibresistant $\mathrm{BCR}-\mathrm{ABL}$ mutations, with the exception of T315I [8]. In vivo, the effective transient dasatinib level might represent a concentration sufficient to inhibit the proliferation of primary ALL cells prior to the emergence of T315I. Our data suggest that a plasma dasatinib concentration that inhibits proliferation of $\mathrm{Ph}+$ cells and induces apoptosis might inhibit the emergence of BCRABL mutations, including T315I, when a resistant T315I clone is not present prior to dasatinib treatment.

In conclusion, lower plasma concentrations of dasatinib were detected among Ph + ALL patients with T315I compared to those without the mutation. These data suggest that sufficient exposure of dasatinib may prohibit clonal evolution by adequately inhibiting BCR-ABL kinase. Future prospective studies with larger sample sizes of Ph + ALL patients are warranted to confirm these results.

\section{Competing interests}

The authors declare no competing financial interests.

\section{Author details}

${ }^{1}$ Dept. of Hematology Nephrology and Rheumatology, Akita Univ. Graduate School of Medicine, Akita, Japan. ${ }^{2}$ Dept. of Pharmacy, Akita Univ. Hospital, Akita, Japan. ${ }^{3}$ Dept. of Genetics and Genomic Sciences, Mount Sinai School of Medicine, New York, NY, USA.

\section{Authors' contributions}

Contribution: NT designed and performed research and wrote the paper MM performed the laboratory analysis; NT, MM, SAS and TN analyzed the data; NT and KS coordinated the study. All authors read and approved the final manuscript.
Received: 13 April 2012 Accepted: 15 May 2012

Published: 15 May 2012

\section{References}

1. O'Hare T, Walters DK, Stoffregen EP, Jia T, Manley PW, Mestan J, Cowan-Jacob SW, Lee FY, Heinrich MC, Deininger MW, Druker BJ: In vitro activity of Bcr-Abl inhibitors AMN107 and BMS-354825 against clinically relevant imatinibresistant Abl kinase domain mutants. Cancer Res 2005, 65:4500-4505.

2. Ottmann $\mathrm{O}$, Dombret $\mathrm{H}$, Martinelli $\mathrm{G}$, Simonsson B, Guilhot F, Larson RA, Rege-Cambrin G, Radich J, Hochhaus A, Apanovitch AM, et al: Dasatinib induces rapid hematologic and cytogenetic responses in adult patients with Philadelphia chromosome positive acute lymphoblastic leukemia with resistance or intolerance to imatinib: interim results of a phase 2 study. Blood 2007, 110:2309-2315.

3. Foa R, Vitale A, Vignetti M, Meloni G, Guarini A, De Propris MS, Elia L, Paoloni F, Fazi P, Cimino G, et al: Dasatinib as first-line treatment for adult patients with Philadelphia chromosome-positive acute lymphoblastic leukemia. Blood 2011, 118:6521-6528.

4. Takahashi N, Miura M, Niioka T, Sawada K: Influence of H2-receptor antagonists and proton pump inhibitors on dasatinib pharmacokinetics in Japanese leukemia patients. Cancer Chemother Pharmacol 2012, 69:999-1004.

5. Nicolini FE, Mauro MJ, Martinelli G, Kim DW, Soverini S, Muller MC, Hochhaus A Cortes J, Chuah C, Dufva IH, et al: Epidemiologic study on survival of chronic myeloid leukemia and $\mathrm{Ph}(+)$ acute lymphoblastic leukemia patients with BCR-ABL T315I mutation. Blood 2009, 114:5271-5278.

6. Soverini S, Vitale A, Poerio A, Gnani A, Colarossi S, lacobucci I, Cimino G, Elia L, Lonetti A, Vignetti M, et al: Philadelphia-positive acute lymphoblastic leukemia patients already harbor BCR-ABL kinase domain mutations at low levels at the time of diagnosis. Haematologica 2011, 96:552-557.

7. Boulos N, Mulder HL, Calabrese CR, Morrison JB, Rehg JE, Relling MV, Sherr CJ Williams RT: Chemotherapeutic agents circumvent emergence of dasatinibresistant BCR-ABL kinase mutations in a precise mouse model of Philadelphia chromosome-positive acute lymphoblastic leukemia. Blood 2011, 117:3585-3595

8. Shah NP, Kasap C, Weier C, Balbas M, Nicoll JM, Bleickardt E, Nicaise C, Sawyers CL: Transient potent BCR-ABL inhibition is sufficient to commit chronic myeloid leukemia cells irreversibly to apoptosis. Cancer Cell 2008, 14:485-493.

doi:10.1186/1756-8722-5-23

Cite this article as: Takahashi et al:: Pharmacokinetics of dasatinib for Philadelphia-positive acute lymphocytic leukemia with acquired T315I mutation. Journal of Hematology \& Oncology 2012 5:23.

\section{Submit your next manuscript to BioMed Central and take full advantage of:}

- Convenient online submission

- Thorough peer review

- No space constraints or color figure charges

- Immediate publication on acceptance

- Inclusion in PubMed, CAS, Scopus and Google Scholar

- Research which is freely available for redistribution 